\title{
Asthma in Hutterites
}

$I^{n}$ $\mathrm{n}$ the present issue of Canadian Respiratory Journal, Rennie, Dosman and Senthilselvan (pages 313-318) report the results of a survey of asthma, allergy and wheeze in rural Saskatchewan schoolchildren that included a number of Hutterites. Questionnaires asking about these conditions and a variety of environmental characteristics, including features of the home and farming activities, were distributed to parents. Response rates were probably high in the non-Hutterites and very high in the Hutterites, who composed about $10 \%$ of the sample ( 83 children).

Clinical geneticists and epidemiologists have studied Hutterites for years because they are a relatively homogeneous population that has always tended to marry and procreate within their own communities. They are, therefore, genetically different from other North Americans.

Not surprisingly, at least to a prairie dweller, Rennie et al show that Hutterites also have a different lifestyle than their rural non-Hutterite neighbours. Hutterites do not smoke, do not live in single-family dwellings, do not have pets in the home and tend not to heat as frequently with natural gas. They also run less specialized farming operations, raising livestock, and cereal and vegetable crops. Hutterite children are raised in communal fashion, in daycare, and are less exposed to grain handling activities than their rural neighbours.

Hutterite parents reported distinctly less doctor-diagnosed asthma in their offspring ( $2.4 \%$ or two children) than did their neighbours $(9.2 \%)$. The apparent prevalence of asthma was relatively high in the control group, compared with other studies, but, even so, it was unusually low in the Hutterites, and comparable with rural children in central Europe. The skeptic might argue that Hutterites are less likely to call the doctor, the essential step in acquiring a diagnosis, and this view appears to be supported by the fact that Hutterite children were less likely to miss school than their neighbours. However, I think that this view is rendered unlikely by the finding that Hutterite children were just as likely to be hospitalized as those of the comparison group, and that hospitalization was a common event, having occurred in over $38 \%$ of both groups. Further, not only was asthma less common in Hutterite children, but both they and their parents had a lower prevalence of allergies than did their rural neighbours,

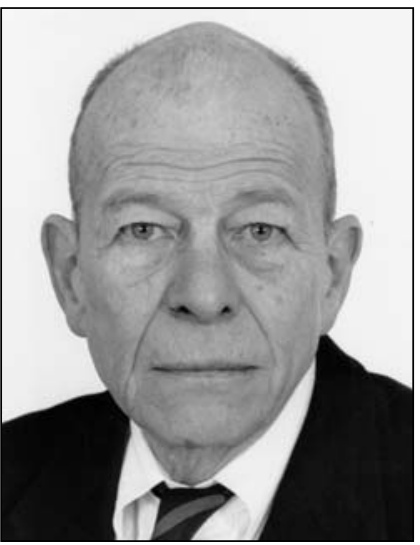

Nick R Anthonisen again arguing that the differences were likely biological.

If we accept that allergy and asthma are relatively uncommon in Saskatchewan Hutterites, how are we to interpret the finding? Rennie et al discuss the matter, and are unable to come to any firm conclusion. Hutterites are genetically different, and this could be the reason. On the other hand, environmental factors could be the reason. Are livestock, the absence of pets, daycare and communal living good for you? Are grain dust, pets, single-family dwellings and natural gas heating bad for you? Is Hutterite daycare comparable with non-Hutterite daycare? Do exposures documented in eight-year-olds represent earlier exposures, which are supposed to be important in the genesis of allergies and asthma? One could go on in this vein for some time.

Thus, we have an interesting and provocative finding that is difficult to interpret with any certainty. In my experience, this situation is very common when addressing the epidemiology of asthma. I am convinced that the chief reason for this is that we do not have an entirely satisfactory definition of the disease. We really do not know 
what asthma 'is' and are, therefore, forced to use operational definitions or surrogates. This can vary from symptoms (wheeze with or without colds) through doctor diagnoses, either from surveys or databases, to measures of airways reactivity, which are difficult and expensive. What one finds depends on the methods used to find it (ie, on the definition used). It is very clear that examining the same population with different definitions of 'asthma' will produce quite different results, and this problem will be with us until we can define the disease adequately. This does not mean that we should stop researching asthma epidemiology, it just means, that like Rennie et al, we have to be careful in our interpretations, and that like Rennie et al, we often are not going to find the definitive answer.

\author{
Nick R Anthonisen MD \\ Editor-in-Chief \\ Canadian Respiratory Journal
}




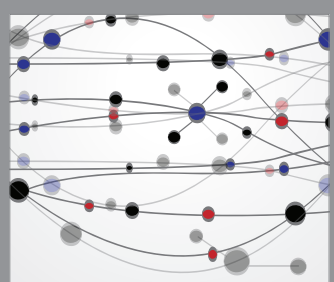

The Scientific World Journal
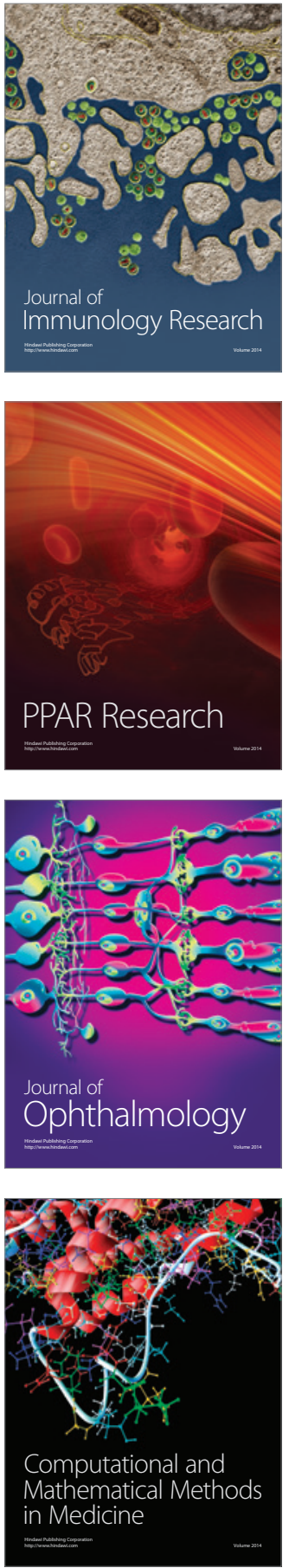

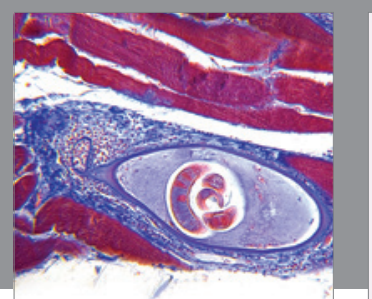

Gastroenterology Research and Practice

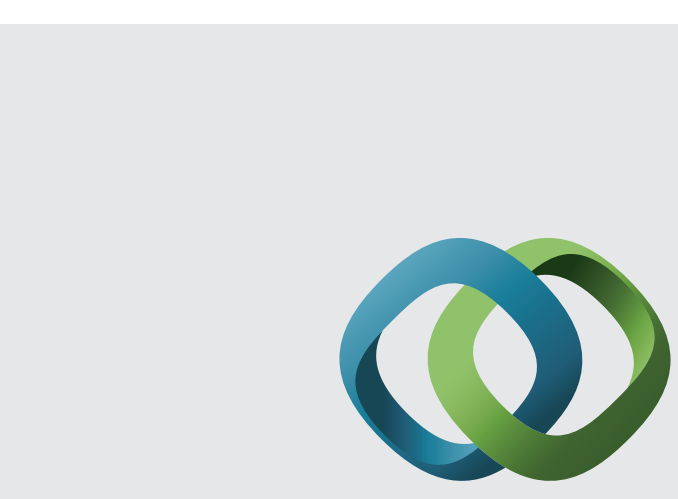

\section{Hindawi}

Submit your manuscripts at

http://www.hindawi.com
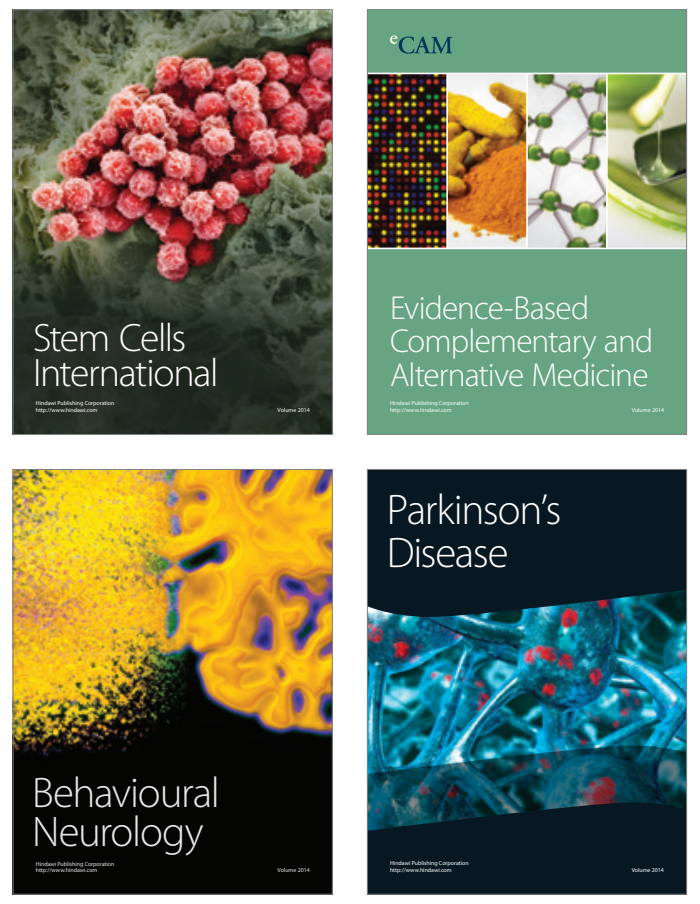
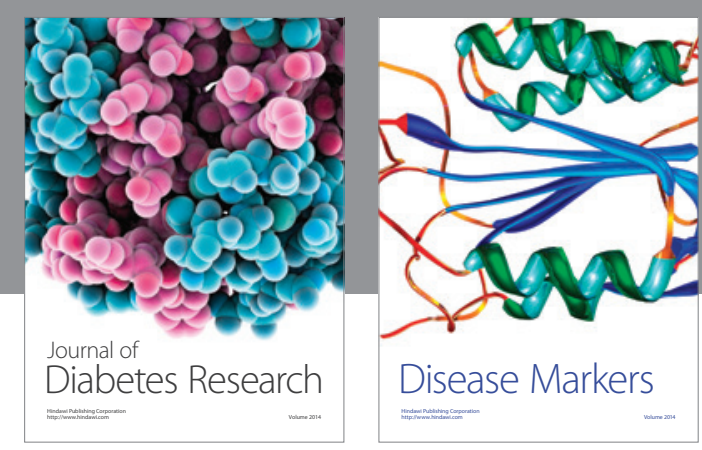

Disease Markers
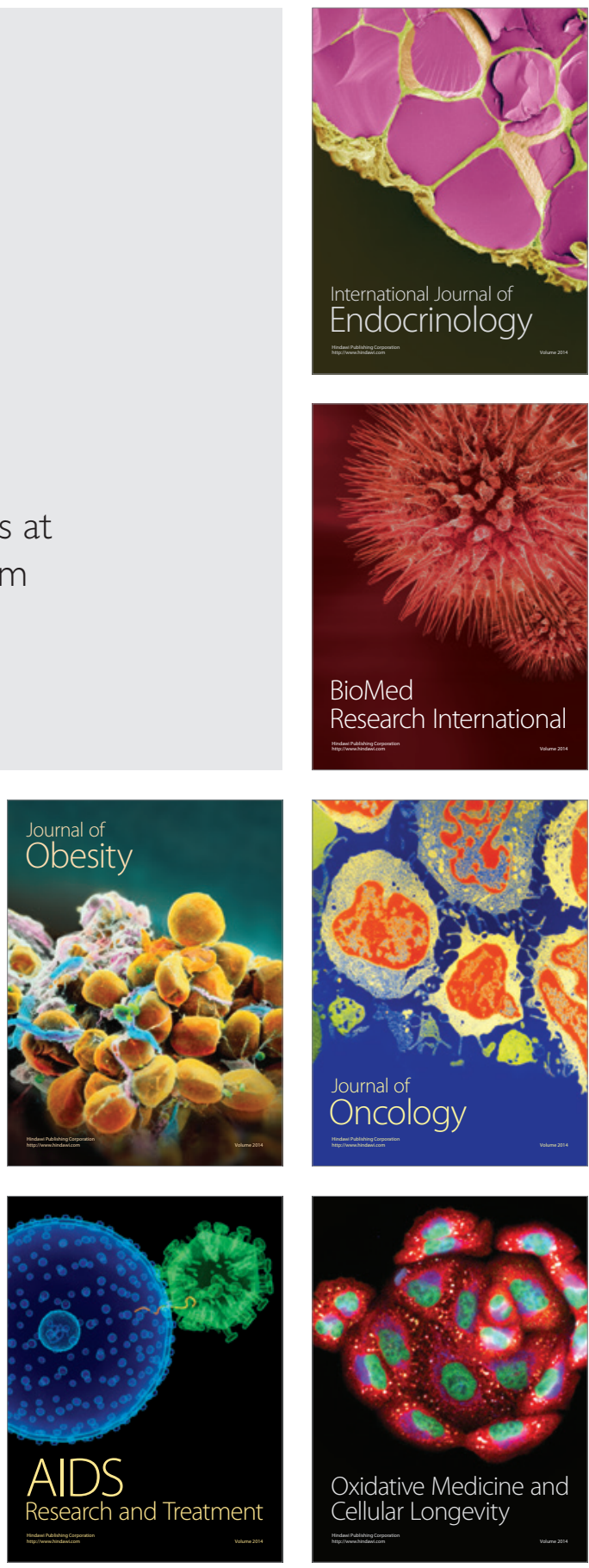